\title{
Mechanical performance of woven kenaf-Kevlar hybrid composites
}

\begin{abstract}
Hybrid composites offer a combination of advantages of constituent components to produce a material with determined properties. In the present work, woven hybrid composite was prepared by hand lay-up method in laminate configuration. Kevlar/kenaf hybrid composites were fabricated with total fibre content of $30 \%$ and the ratio of Kevlar/kenaf varies in weight fraction of $78 / 22,60 / 40,50 / 50,26 / 74$, and 32/68, respectively. The Kevlar/epoxy and kenaf/epoxy were also prepared for comparison. The mechanical properties of hybrid, kenaf/epoxy, and Kevlar/epoxy composites were tested. Morphological properties of tensile fracture surface of hybrid composites were studied by scanning electron microscopy. Results have established that the mechanical properties of kenaf-Kevlar hybrid composites are a function of fibre content. The hybrid composites with Kevlar/kenaf (78/22) ratio exhibited better mechanical properties compared to other hybrid composites. This result indicates the potential of Kevlar-kenaf hybrid composite for impact applications.
\end{abstract}

Keyword: Woven kenaf; Kevlar; Hybrid composites; Mechanical properties 